\title{
Macroscopic and microscopic effects of elevated temperatures on unrestored and restored teeth: An in-vitro forensic study
}

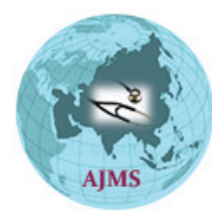

\author{
Sandeep Sharma \\ Lecturer, Department of Oral Pathology, Microbiology, and Forensic Odontology, College of Medical Sciences and \\ Teaching Hospital, Bharatpur, Chitwan, Nepal
}

Background: The present "in vitro" study was done to observe the effects of high temperatures on teeth restored with different restorative materials and unrestored teeth. Aim and Objective: This study aims to investigate the nature of damage to unrestored and restored teeth subjected to high temperatures. The main objective of the study is to assess whether it could serve as an aid in identification of human dental remains in forensic odontology for cases of incineration by means of comparison between ante-mortem and post-mortem records. Materials and Methods: The present study was conducted on 125 extracted premolar teeth which were later on divided into five groups (25 premolar teeth each) as control group, group of teeth restored with class I amalgam restorations, group of teeth restored with class I composite/ adhesive system restorations, group of teeth restored with Class I glass ionomer restoration and group of teeth restored with metal ceramic crown restored teeth. The restored teeth were placed in a furnace and heated at a rate of $10^{\circ} \mathrm{C} / \mathrm{min}$. The effects of the predetermined $200^{\circ} \mathrm{C}$, $400^{\circ} \mathrm{C}, 600^{\circ} \mathrm{C}, 800^{\circ} \mathrm{C}, 1000^{\circ} \mathrm{C}$ and $1200^{\circ} \mathrm{C}$ temperatures were examined macroscopically and then microscopically by means of a stereomicroscope.Data obtained in the present study was subjected to the statistical analysis using SPSS 18 software for one-way ANOVA and independent t-test (paired). Result: The class I restorations made of amalgam could be identified till $1200^{\circ} \mathrm{C}$ because they maintain their shape despite the disintegration of the crowns along with PFM restoration with disintegration of remaining restorations along with tooth. Systematic approach toward the preservation of charred dentition, as at times could prove to be the best evidence for identification of those who are extensively burned. Conclusion: Pre-planned and systematic approach toward the preservation of charred dentition is important as at times it could act as a potential evidence for the identification of those who are severely burnt.

Key words: Dental identification; Forensic sciences; Temperatures
Access this article online

Website:

http://nepjol.info/index.php/AJMS

DOI: 10.3126/ajms.v11i2.26364

E-ISSN: 2091-0576

P-ISSN: 2467-9100

\section{INTRODUCTION}

The science of dentistry as related to the law is known as forensic dentistry or forensic odontology. Forensic dentistry involves dentist's participation in assisting legal and criminal issues focussing mainly on identification of human beings, in cases of mass disaster where the dead body is usually badly mutilated.

Comparative Dental identification involve use of both antemortem and post mortem records to assist in identifying the victims of violence, disaster or other mass tragedies. ${ }^{1}$ In many cases the tentative identification of the individual is unknown the correlation of dental records to observed restorative treatment provides the best evidence for investigation of unknown remains. ${ }^{1}$

Teeth are the indestructible components of the human body and have unique highest resistance to most of the environmental effects like fire, desiccation, decomposition. ${ }^{1}$ Norlander classified body burns in five categories: (1) superficial burns, (2) destroyed epidermis areas,

Address for Correspondence:

Dr. Sandeep Sharma, Lecturer, Department of Oral Pathology, Microbiology, and Forensic Odontology, College of Medical

Sciences and Teaching Hospital, Block-C, Dental Program, Bharatpur-10, Chitwan, Nepal. Phone: +977 9844469555.

E-mail: sandeepsharma@cmsnepal.edu.np

ㄷ) Copyright AJMS 
(3) destruction of the epidermis and dermis and necrosis areas in underlying tissues, (4) total destruction of the skin and deep tissues and (5) burned remains. Since the destruction of burned victims of the third, fourth and fifth category, is extensive, such remains cannot be identified by conventional methods like visual recognition or fingerprints.

Therefore, in cases of natural as well as man-made disasters, teeth help in positive personal identification for victims in an otherwise unrecognizable body. ${ }^{2}$ The present study was conducted to observe the effects of high temperatures on teeth restored with different restorative materials and unrestored teeth.

\section{Aims}

1. To evaluate and compare the macroscopic \& microscopic features of unrestored, restored and endodontically treated extracted teeth, before and after exposure to an experimental range of high temperatures.

2. To investigate the nature of damage to unrestored and restored teeth subjected to high temperatures.

\section{Objectives}

1. To assess whether the study can serve as an aid in identification of human dental remains in forensic odontology for cases of incineration by means of comparison between ante-mortem and post-mortem records

2. To evaluate whether the study can highlight the significance of microscopic study of dental tissues as a determinant of tooth and thereby using structural damage to dental tissues as a valuable clue to the nature and severity of fire for criminal investigations.

\section{MATERIALS AND METHODS}

This study was conducted at Department of Pathology, College of Medical Sciences-Teaching Hospital, Bharatpur, Chitwan, Nepal. Ethical clearance (IRC-Ref No.:2019-037) was obtained from the institutional review committee. One hundred twenty-five non-carious teeth, extracted for orthodontic reasons were selected for this study. Teeth were then disinfected in a 5\% sodium hypochlorite solution for 1 hour and then stored in sodium chloride $0.9 \%$ solution at $37^{\circ} \mathrm{C}$ for up to 15 days. These were then divided into two groups Group I (control group=25 teeth) and Group II (restored teeth $=100$ teeth). Class I Cavities (faciolingual width $1-1.5 \mathrm{~mm}$ and a depth of $1.5-2 \mathrm{~mm}$ ) were prepared in group II teeth and these were restored and further subdivided into four sub groups based on restoration present in them as -

Sub group A: Amalgam (DPI) restored teeth (25 extracted teeth).
Subgroup B: Composite (Dentsply) restored teeth (25 extracted teeth).

Subgroup C: Glass Ionomer Cement (Type 2 Restorative material --GC Corporation) restored

teeth (25 extracted teeth).

Subgroup D: Metal Ceramic Crown restored teeth (25extracted teeth).

After restoration were done all the teeth of Group I and Group II were then again immersed in $0.9 \% \mathrm{NaCl}$ solution at $37^{\circ} \mathrm{C}$ for 15 days. After 15 days these teeth were then taken out from $\mathrm{NaCl}$ solution. Then mesio-distal dimension of the teeth of both groups were then recoded with the help of digital Vernier calliper (Yamayo japan).All these teeth were then mounted on blocks made by phosphate bonded investment material. Then all these teeth were then exposed to different temperatures $200^{\circ} \mathrm{C}, 400^{\circ} \mathrm{C}, 600^{\circ} \mathrm{C}$, $800^{\circ} \mathrm{C}, 1000^{\circ} \mathrm{C}$, and $1200^{\circ} \mathrm{C}$ in muffle ceramic furnace (TEMP $1400^{\circ} \mathrm{C}$ Unident). The temperature of the furnace was changed at the constant rate of 10 degrees centigrade/ minute. As soon as each target temperature $\left(200^{\circ} \mathrm{C}, 400^{\circ} \mathrm{C}\right.$, $600^{\circ} \mathrm{C}, 800^{\circ} \mathrm{C}, 1000^{\circ} \mathrm{C}$, and $1200^{\circ} \mathrm{C}$ ) was reached, the corresponding set were removed and allowed to cool at room temperature. Before exposing the teeth to higher range of temperature the furnace was preheated to previous temperature and then when that temperature was reached the teeth were placed for next cycle of higher temperature.

The teeth and restorations were then analyzed macroscopically by direct vision of the samples and finally by stereomicroscope using the following parameters-:

\section{For teeth}

1. Size of the crown (Mesiodistal width of the crown)

2. Color of the crown (from yellowish white or whitish yellow $\rightarrow$ brown $\rightarrow$ black $\rightarrow$ greyish blue $\rightarrow$ chalky white)

3. Cracks and fissures in the crown (Present or Absent)

4. Fragmentation and fractures in the crown. (Present or Absent).

\section{For restorations}

1. Shape of the restoration

2. Presence of cracks or fissures (Absent or Present)

3. Shattering or detachment of the filling from the tooth. (Present or Absent).

\section{RESULTS}

After exposing the extracted teeth of both the Group I (unrestored) \& Group II (restored) to $200^{\circ} \mathrm{C}-1200^{\circ} \mathrm{C}$ temperatures the macroscopic variations (Tables 1-5) were recorded by visual examination. Along with the macroscopic examination, stereomicroscopic assessment 
(Table 6 and 7) was also done at different temperatures to analyse the microscopic changes (Figures 1-8).

Estimation of mesiodistal diameter of teeth was done to analyse the loss of tooth material when being exposed to different graded high temperatures which indicated that for all the groups and subgroups there was decrease in mesiodistal dimension at increased temperatures except for Sub group D (metal ceramic restored teeth) where after $600^{\circ} \mathrm{C}$ there was increase in the mesio-distal dimension. Shrinkage was observed in the tooth material as the temperature was increased. In all the groups and sub groups positive shrinkage was observed but in case of Sub group D (metal ceramic restored teeth) negative shrinkage was seen which meant increase in the dimensions of the concerned tooth. Change in the colour of the crown was observed on exposure to increased temperature from yellowish white or whitish yellow $\rightarrow$ brown $\rightarrow$ black $\rightarrow$ greyish blue $\rightarrow$ chalky white. There was observable change in the color of the root also. Fragmentation of the crown of the extracted teeth was seen in all groups and sub groups except Sub group D (metal ceramic restored teeth) at temperature above $400^{\circ} \mathrm{C}$. In case of Sub Group D (metal ceramic restored teeth) surface of crown showed mere crackling. Cracks were observed on the surface of the crown and root of teeth of all the groups and sub groups from and after $400^{\circ} \mathrm{C}$ except for Sub group D (metal ceramic restored teeth) where cracks were observed from and after $600^{\circ} \mathrm{C}$.

Data obtained in the present study was subjected to the statistical analysis using SPSS 18 software for oneway ANOVA and independent t-test (paired) and was subsequently done to ascertain the mean and standard error of mean of experimental groups.

Estimation of Mesiodistal dimension of the teeth was also done using a Vernier caliper. The results were interpreted on the basis of comparison between different groups in terms of loss of tooth material by comparing the Mesiodistal dimensions with those obtained after exposure to higher temperature.

\section{DISCUSSION}

Fire investigation is the multidisciplinary basis of the exploration, which involves investigations concerning the origin of fire, its cause as well as the identification of victims. ${ }^{2}$ At times, victim identification in fire disasters becomes nearly impossible owing to complete destruction. ${ }^{3}$ The teeth used in the experiments described should were of the same type in order to enable comparison between observations at different temperatures. For our study premolar teeth were chosen. These premolar teeth were those which have been

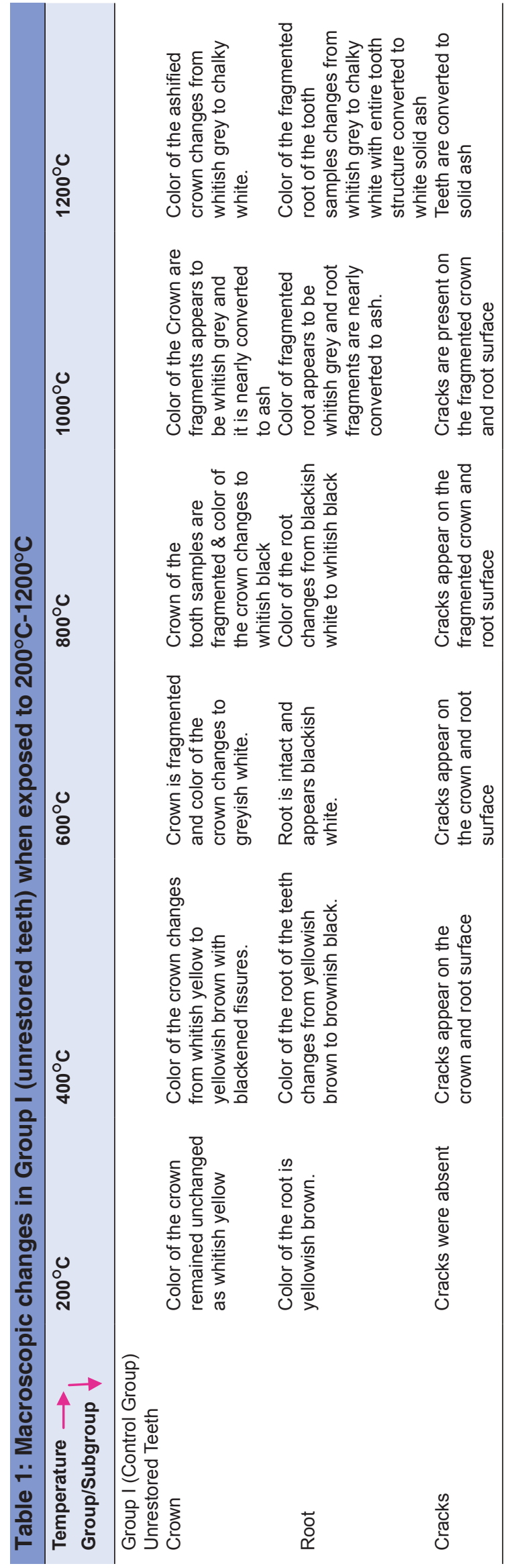




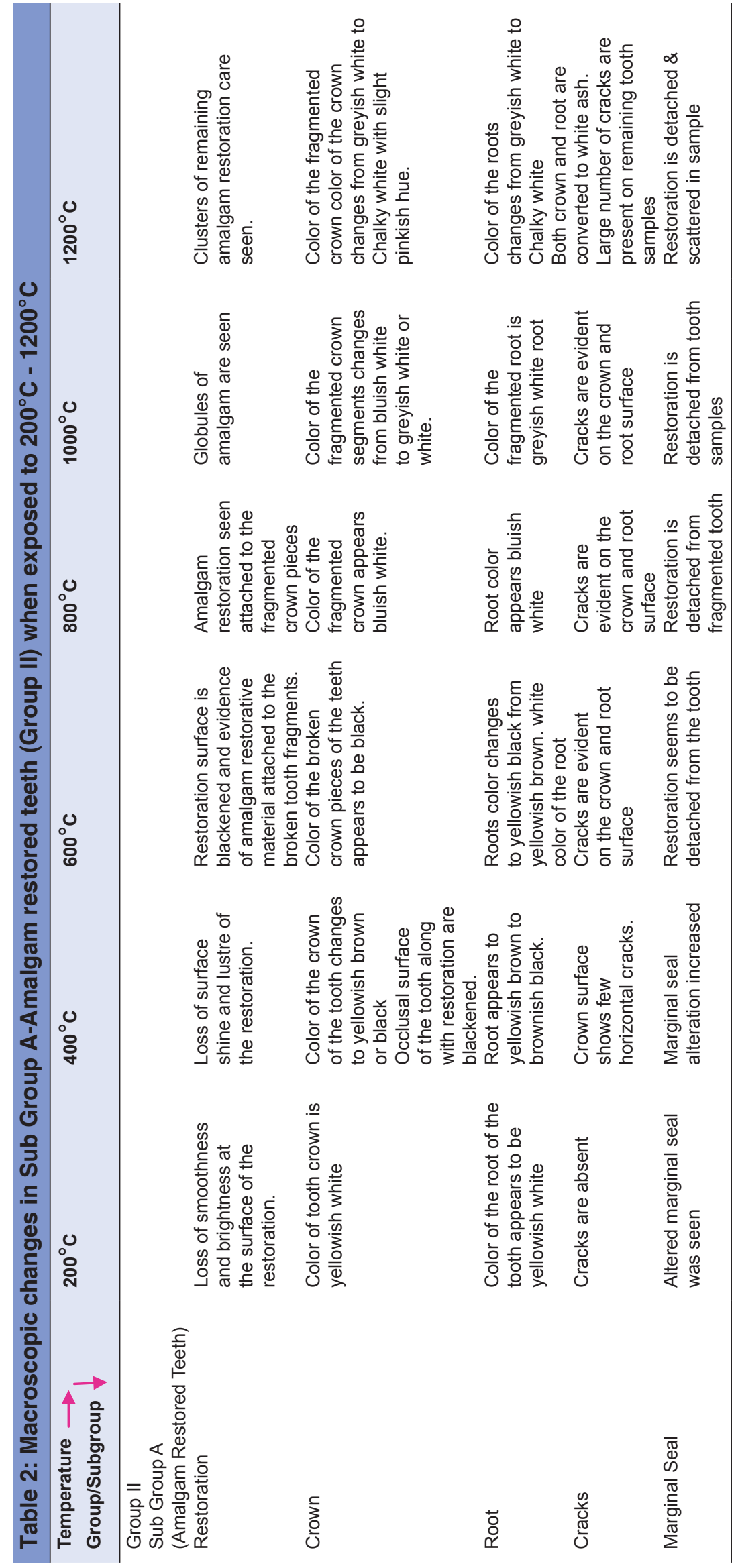




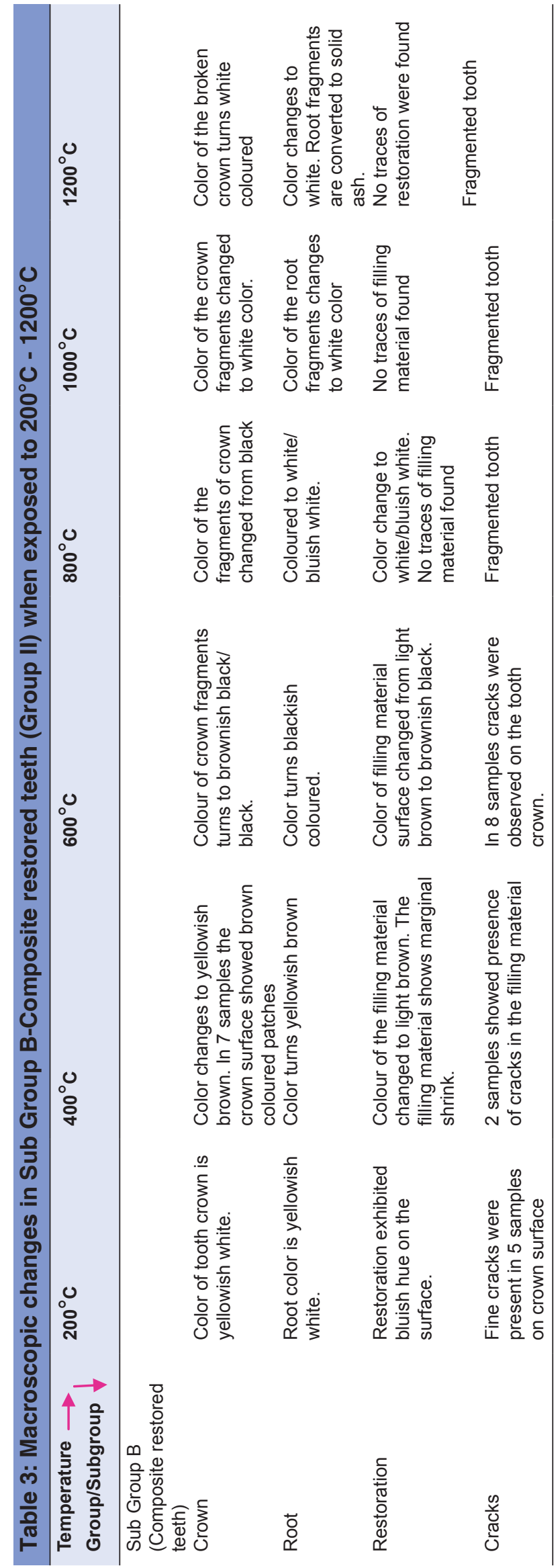

extracted as part of orthodontic treatment and also because they were free from decay. The choice of premolar teeth was considered to be appropriate as premolars belong to the pluri-radicular group and also these are better preserved in a fire than incisor teeth, which are rapidly destroyed. ${ }^{4}$

Merlati et al (2002) ${ }^{5}$ in their study found that unrestored teeth when exposed to $200^{\circ} \mathrm{C}$, showed alteration in the colour from yellowish white to light yellowish brown. In our study at $400^{\circ} \mathrm{C}$ the colour of root was brownish black. Our study showed that at $600^{\circ} \mathrm{C}$ the crown was fragmented and the root was intact with dark brown colour with black stains which was in accordance with study done by Bagdey et al (2014). ${ }^{6}$ Stereomicroscopy $(20 \mathrm{X})$ at $400^{\circ} \mathrm{C}$ revealed micro-fractures and cracks on the crown and root surface which was similar to the findings of Merlati et al $(2002) .{ }^{5}$ At $600^{\circ} \mathrm{C}$ the colour of crown fragments in our study was found to be dark brown with black pigmentation which was in accordance with study done by Moreno et al (2009). ${ }^{3}$ Stereomicroscopy (20x) at $600^{\circ} \mathrm{C}$ revealed numerous minute fractures on the root which was similar to findings of study by Bagdey et al (2014). ${ }^{6}$ In our study at $800{ }^{\circ} \mathrm{C}$ the colour of crown and root of the unrestored teeth was greyish which was contrary to findings of Merlati et al (2002). ${ }^{5}$ Stereomicroscopy (20X) at $800^{\circ} \mathrm{C}$ in our study showed presence of vertical cracks on the root surface. Stereomicroscopy $(20 \mathrm{X})$ at $1000^{\circ} \mathrm{C}$ in our study showed numerous micro- fractures which was in accordance with findings of Merlati et al (2002). ${ }^{5}$

The results of study done by Moreno et al $(2009)^{3}$ revealed that composite fillings could be identified till $800^{\circ} \mathrm{C}$ and amalgam fillings till $1000^{\circ} \mathrm{C}$ but it was contrary to our study findings where the composite restoration could be identified till $600^{\circ} \mathrm{C}$ only and the amalgam restoration was identifiable till $1200^{\circ} \mathrm{C}$. The amalgam in our study showed loss brightness, marginal seal and bubbles on the surface at $200^{\circ} \mathrm{C}$ which was in accordance with study done by Merlati et al; (2004), ${ }^{7}$ Moreno et al; (2009), ${ }^{3}$ Vazquez L et al (2012). ${ }^{8}$ The loss of the marginal seal was due to the evaporation of mercury and loss of organic matrix. Bubble formation on the restoration surface indicated the evaporation of mercury on exposure to high temperature.

In our study at $400^{\circ} \mathrm{C}$ the colour of the crown was light brown or black which was simulated findings of the study by Merlati et al (2004). ${ }^{7}$ The black appearance of the crown was due to the carbonization process. ${ }^{10}$ Stereomicroscopy (20x) at $400^{\circ} \mathrm{C}$ showed loss of marginal seal which was similar to findings of Bagdey et al; (2014). ${ }^{6}$ At $600^{\circ} \mathrm{C}$ amalgam showed opaque blackened appearance which matched findings of study by Moreno et al (2009). ${ }^{3}$

Moreno et al $(2009)^{3}$ in their study found that at $800^{\circ} \mathrm{C}$ amalgam restoration shows corrugated surface with fissures 
Sharma: Heat, teeth and forensic identification

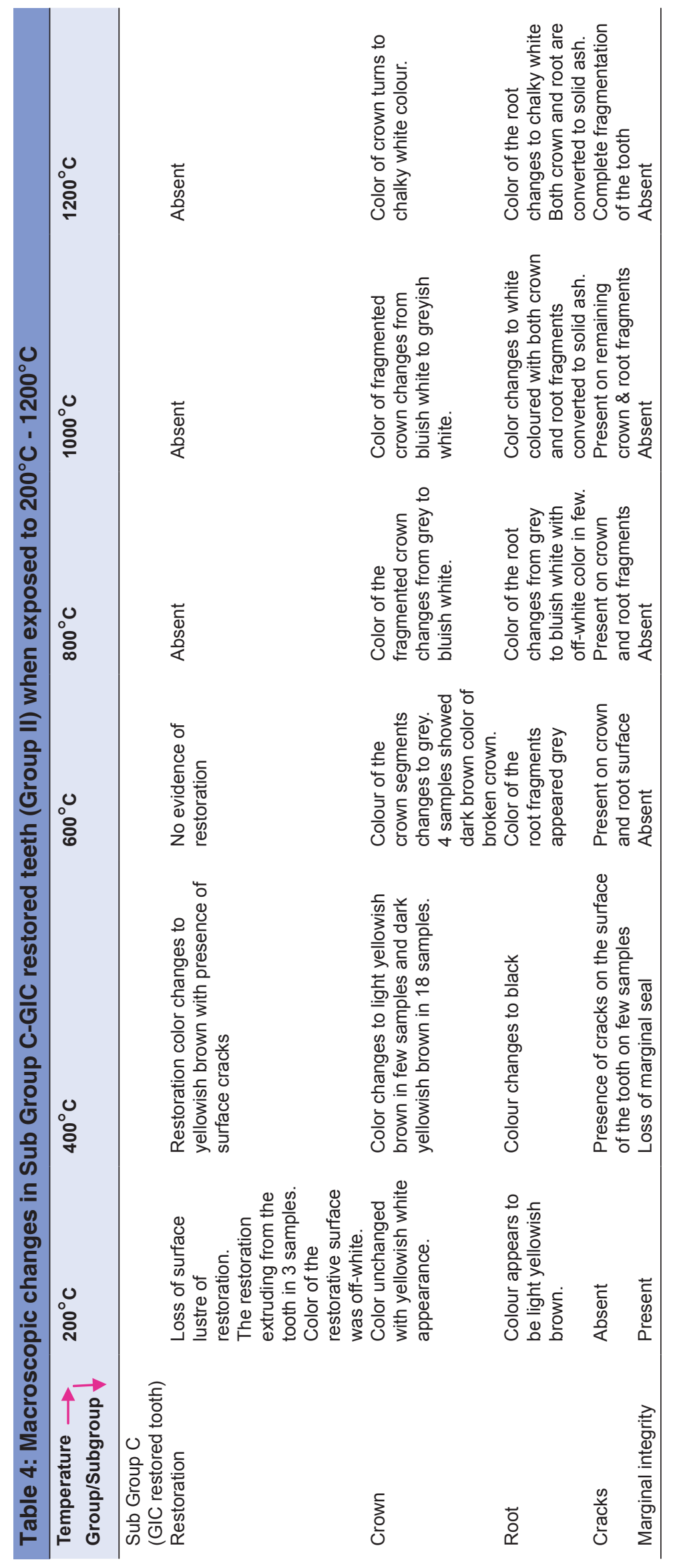



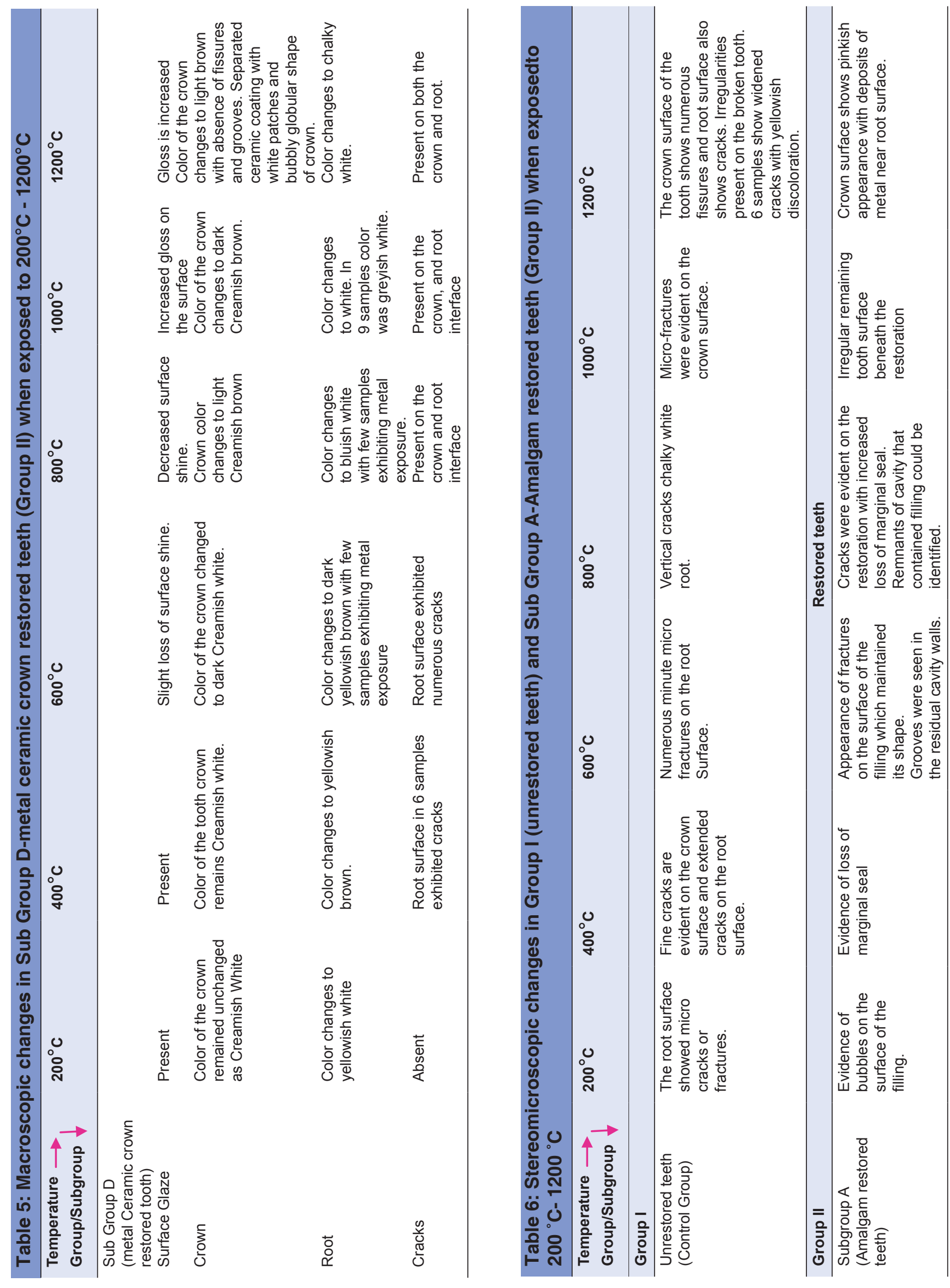


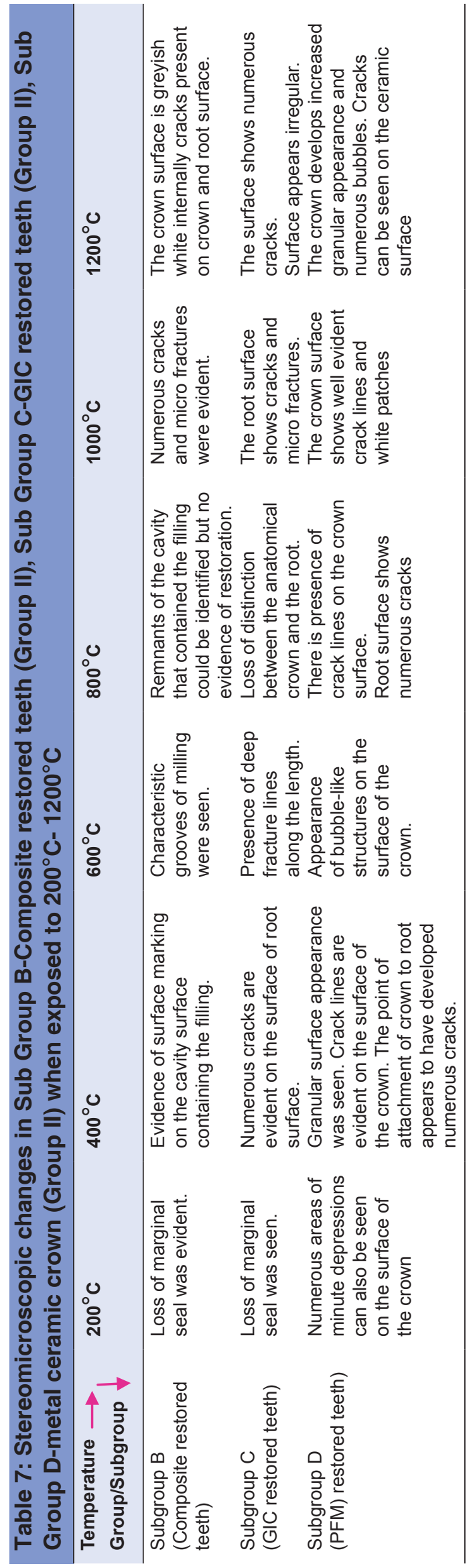

but this finding was absent in our study. In study by Merlati et al $(2002)^{5}$ the crown was fragmented and restoration was recovered at some distance from shattered tooth and this was in accordance with the findings or our study. In our study at $800^{\circ} \mathrm{C}$ globules of amalgam restoration termed as "silver bullets" were absent which were seen in studies by Vazquez L et al (2012) ${ }^{8}$, Moreno et al (2009). ${ }^{3}$ In our study Stereomicroscopy $(20 \mathrm{X})$ at $400^{\circ} \mathrm{C}$ revealed loss of marginal seal which was in accordance with study by Bagdey et al (2014). ${ }^{6}$ Study by Moreno et al (2009) presented with one finding of presence of golden thread that surrounds the occlusal surface and cusps between $800^{\circ} \mathrm{C}-1200^{\circ} \mathrm{C} .^{3}$ This feature was absent in our study.

In our study at $200^{\circ} \mathrm{C}$ the stereomicroscopy (20X) showed loss of marginal seal which was similar to findings of study done by Merlati et al (2002). ${ }^{5}$ When the composite resin restored tooth was heated further to $400^{\circ} \mathrm{C}$ the colour of restoration changed to light brown and this finding was in accordance with study done by Vazquez L et al (2012). ${ }^{8}$ In our study marginal retraction and cracks were observed in composite resin at $400^{\circ} \mathrm{C}$ which was in accordance with study done by Vazquez L et al; (2012). ${ }^{8}$ Stereomicroscopy (20X) at $400^{\circ} \mathrm{C}$ showed cavity surfaces containing the composite with numerous surface markings which was in accordance with findings of Merlati et al (2002). ${ }^{5}$ In our study composite restoration was non identifiable after $600^{\circ} \mathrm{C}$ which was in accordance with study by Merlati et al $(2002)^{5}$ but was contrary to results of studies by Vazquez L et al (2012). ${ }^{8}$ Stereomicroscopy $(20 \mathrm{X})$ at $600^{\circ} \mathrm{C}$ showed characteristic grooves created due to instrumentation and this findings was similar to findings of Merlati et al (2002). ${ }^{5}$ Stereomicroscopy $(20 \mathrm{X})$ at $800^{\circ} \mathrm{C}$ showed the outlines of cavity remnants and this was similar to findings of Merlati et al (2002). ${ }^{5}$ Stereomicroscopy $(20 \mathrm{X})$ at $1000^{\circ} \mathrm{C}$ in our study showed numerous cracks and micro-fractures on the root surface which was similar to findings of study by Merlati et al(2002). ${ }^{5}$

In our study at $200^{\circ} \mathrm{C}$ loss of marginal seal was seen with a stereomicroscope (20X) and this finding was in accordance with study done by Bagdey et al(2014). ${ }^{6}$ In our study at $400^{\circ} \mathrm{C}$ the colour of the crown and Glass Ionomer Cement restoration changed to yellowish brown and colour of the root changed to black. These findings were in accordance with study done by Bagdey et al (2014). ${ }^{6}$

Metal Ceramic crowns in our study at $600^{\circ} \mathrm{C}$ showed slight discolouration with pitted surface with exposure of underneath metal. These findings were in accordance with findings of study done by Patidar et al (2010) $\cdot{ }^{11}$ In our study at $1200^{\circ} \mathrm{C}$ the ceramic overflowed with loss of morphology of the crown. There was change of glaze along with separation of ceramic small flakes along with discolouration. There crown was complete displaced from root. The crown showed 


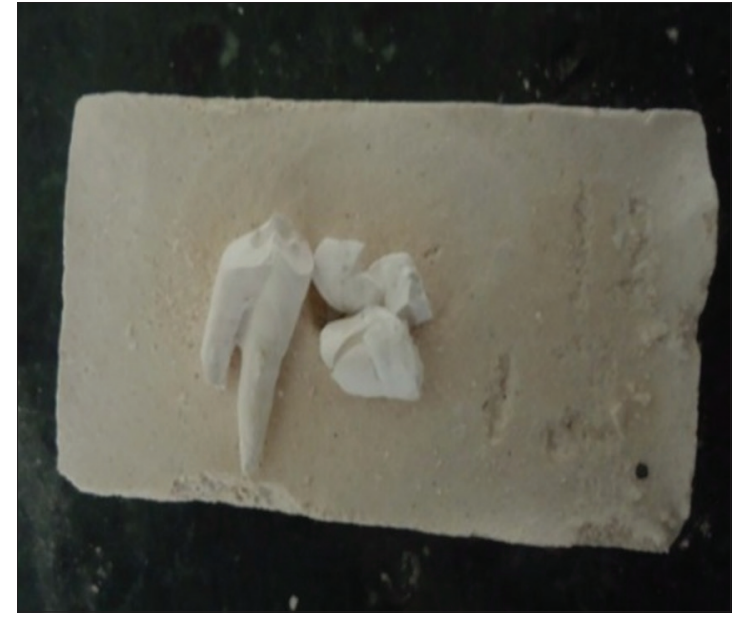

Figure 1: Macroscopically fragmented chalky white crown and chalky white root observed in unrestored teeth at $1200^{\circ} \mathrm{C}$

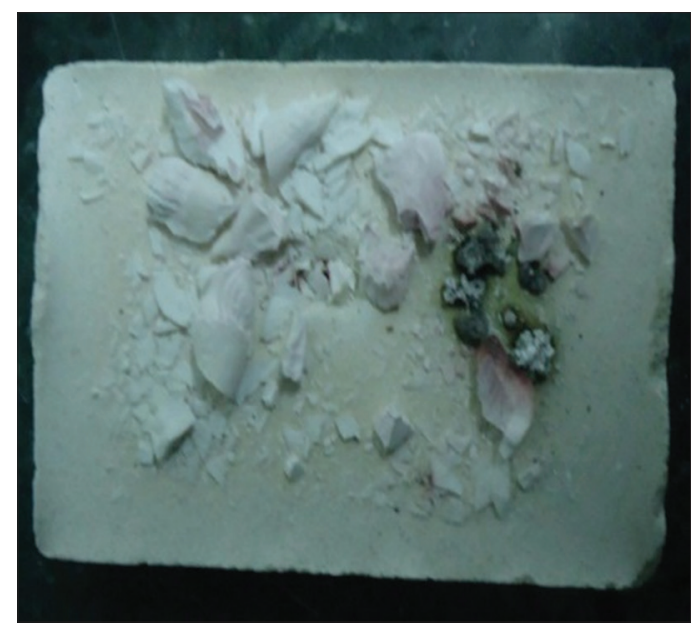

Figure 2: Macroscopically chalky white crown and root with small clusters of restoration observed in amalgam restored teeth at $1200^{\circ} \mathrm{C}$

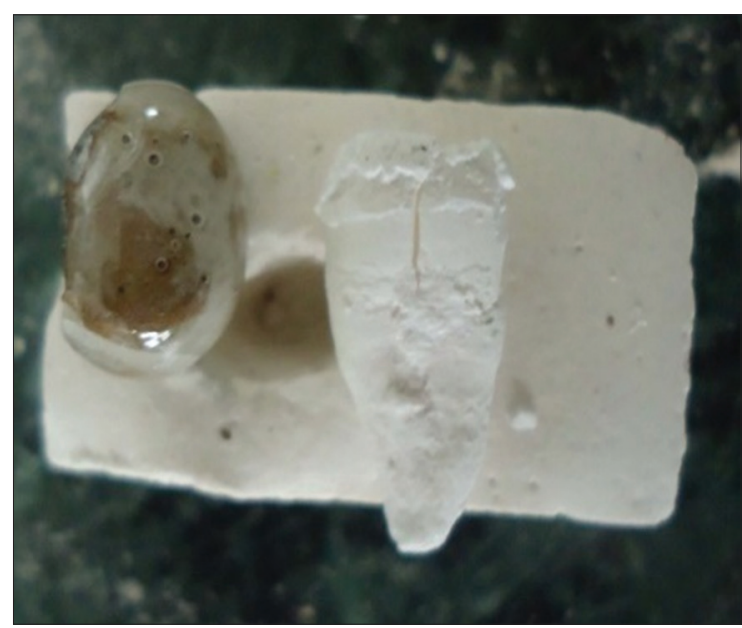

Figure 3: Macroscopically globular shaped crown with loss of surface morphology and white coloured root surface in metal ceramic crown restored teeth observed at $1200^{\circ} \mathrm{C}$

patchy pattern. ${ }^{12}$ These findings were similar to findings of study by Patidar et al (2010). ${ }^{11}$ The metal ceramic crowns due

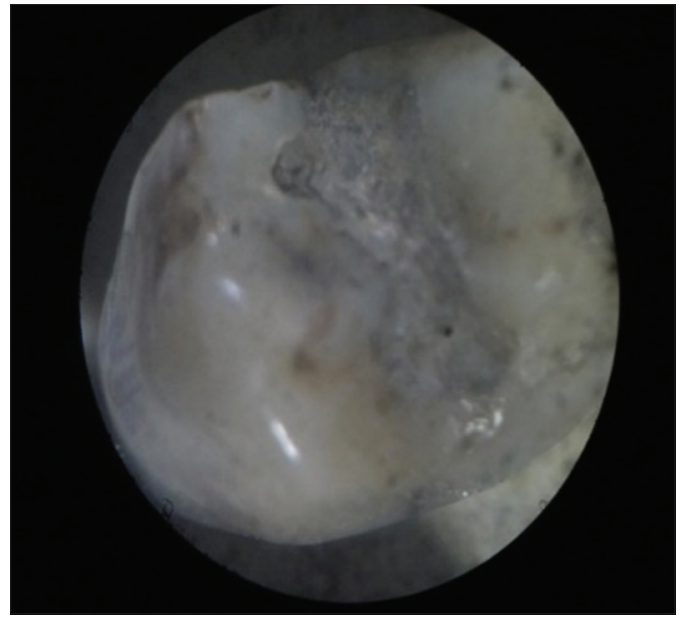

Figure 4: Steromicroscopically loss of marginal seal of the restoration in amalgam restored tooth observed at $400^{\circ} \mathrm{C}$

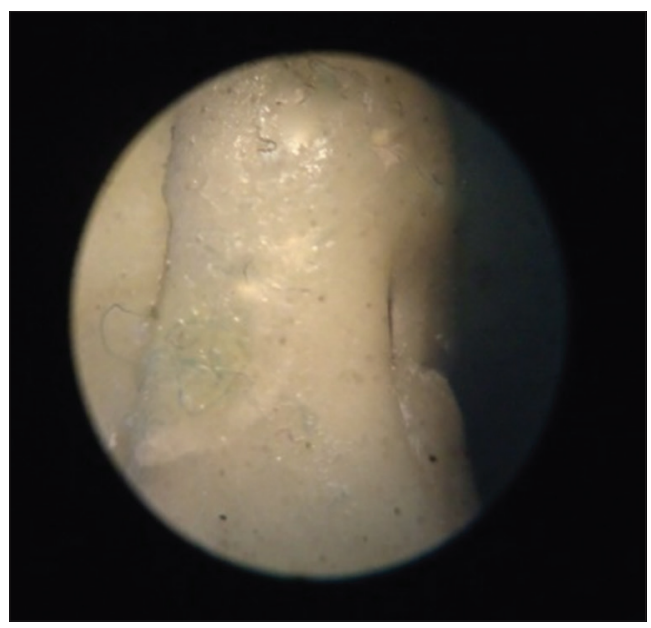

Figure 5: Steromicroscopically crown surface with pinkish appearance and clusters of restoration observed in amalgam restored tooth at $1200^{\circ} \mathrm{C}$

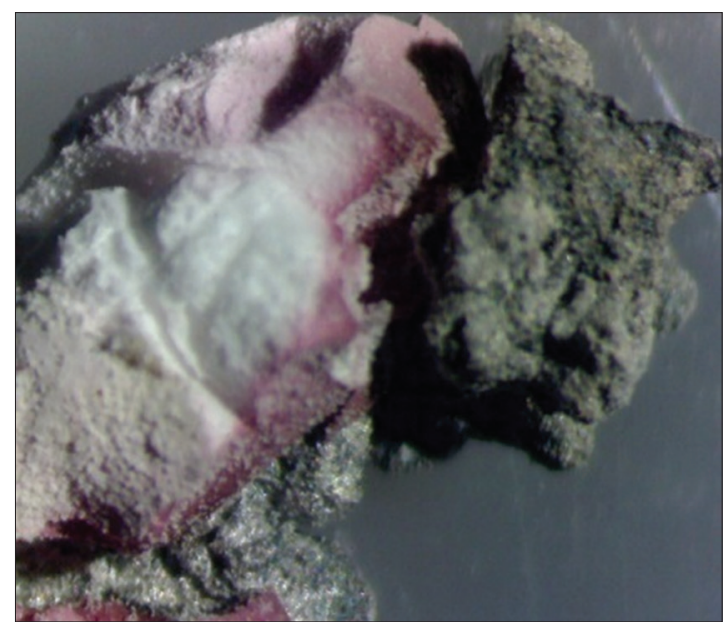

Figure 6: Steromicroscopically loss of marginal seal of the restoration in GIC restored tooth observed at $200^{\circ} \mathrm{C}$

to their high strength and resistance to wear resisted exposure to high temperature without undergoing many changes. 


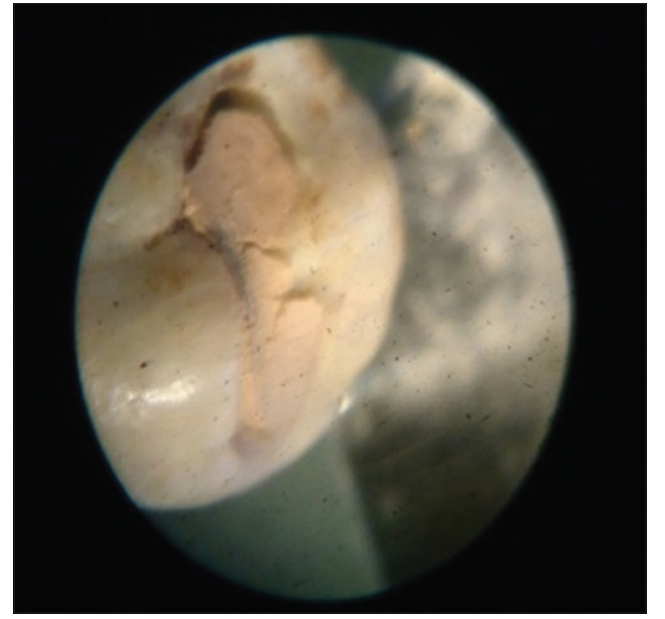

Figure 7: Steromicroscopically granular appearance on the surface of the crown of metal ceramic crown restored tooth observed at $400^{\circ} \mathrm{C}$

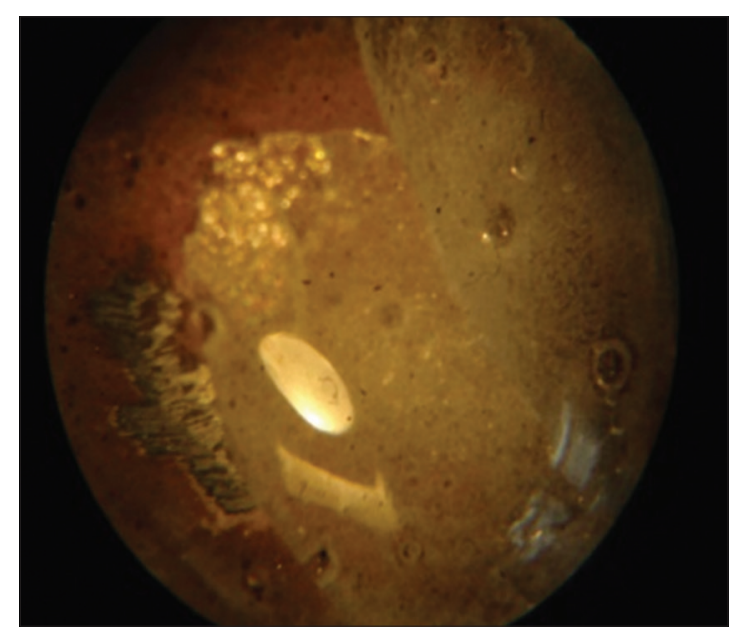

Figure 8: Steromicroscopically globular shaped crown with presence of granularity, numerous bubbles and cracks on the surface of metal ceramic crown restored tooth observed at $1200^{\circ} \mathrm{C}$

When the teeth whether unrestored or restored were heated there occurs reduction in the mesio-distal dimension of tooth or in other words there occurs shrinkage of tooth material. ${ }^{13}$ The average volumetric shrinkage when observed radiographically between $400^{\circ} \mathrm{C}-1000{ }^{\circ} \mathrm{C}$ ranged from $4.78 \%$ to $32.53 \% .^{14}$

In our study also the assessment of the mesio-distal diameter of the tooth was done with the help of digital Vernier calliper and on the basis of the mesio-distal dimension obtained percentage shrinkage was calculated using the formula: ${ }^{14}$

$\%$ Shrinkage $=[($ Original dimension- Altered dimension $) /$ original dimension] $\mathrm{x} 100^{14}$

Abnormal behaviour was seen in case of metal ceramic crown restored teeth it was seen that the $\%$ shrinkage showed fluctuating pattern with a decrease from preheating $-600^{\circ} \mathrm{C}$ and after that there was increase in the dimension of crown when the temperature was increased from $600^{\circ} \mathrm{C}-1200^{\circ} \mathrm{C}$. The increase in the dimension after are due to the expansion of metal underneath followed by overflowing of overlying ceramic.

In our study, once the pre-determined temperatures were reached, the samples were removed from the oven and allowed to cool at room temperature. The materials were therefore subjected to only one controlled and limited thermal shock..$^{14}$

The teeth are known to survive higher temperatures and the effect of heat on teeth in reality is further complicated by the duration of exposure to high temperatures. As the teeth show resistance to the higher temperatures they could be efficiently used as a tool for forensic investigations. ${ }^{7}$

\section{CONCLUSION}

The progressive colour alterations and the values of average shrinkage it might be possible to predict the ante- mortem size of the teeth, thereby supporting the odontological identification process in cases where only isolated teeth are present. Of the all dental filling restorative materials amalgam has the potential to resist up to $1200^{\circ} \mathrm{C}$ temperature. Other restorative filling materials like Composite, GIC were not able to show enough resistance against high temperature. Metal ceramic crown start showing change after $800^{\circ} \mathrm{C}$ by development of crack lines and exposure of underneath metal and at $1200^{\circ} \mathrm{C}$ it starts cracking.

This study highlighted the importance of the pre-planned and systematic approach toward the preservation of charred dentition, as at times it could act as a potential evidence for the identification of those who are severely burnt.

\section{REFERENCES}

1. Hautzinger $Z$. The present and the future of forensic identification. Jurisprudencija 2005; 66(58); 99-105.

2. Savio C, Merlati G, Danesino P, Fassina G and Menghini P. Radiographic evaluation of teeth subjected to high temperatures: Experimental study to aid identification processes. Forensic Science International 2006; 158(2-3):108-116.

3. Moreno S, Merlati G, Marin L, Savio C and Moreno F. Effects of high temperatures on different dental restorative systems: Experimental study to aid identification processes. Journal of Forensic Dental Sciences 2009; 1(1):17-23.

4. Eckert WG, James $S$ and Katchis $S$. Investigation of cremations and severely burned bodies. The American journal of forensic medicine and pathology 1988; 9(3):188-200.

5. Merlati G, Danesino P, Savio C, Fassina G, Osculati A and Menghini P. Observations on dental prostheses and restorations subjected to high temperatures: experimental studies to 
aididentification processes. The Journal of forensic odontostomatology 2002; 20(2):17-24.

6. Bagdey SP, Moharil RB, Dive AM, Thakur S, Bodhade A and Dhobley AA. Effect of various temperatures on restored and unrestored teeth: A forensic study. Journal of forensic dental sciences 2014; 6(1):62.

7. Merlati G, Savio C, Danesino P, Fassina G and Menghini P. Further study of restored and un-restored teeth subjected to high temperatures. Journal of Forensic Odonto Stomatology 2004; 22(2):34-39

8. Vazquez L, Rodríguez $\mathrm{P}$ and Moreno F. In vitro macroscopic analysis of dental tissues and somedental materials used in endodontics, submitted to high temperatures for forensic applications. Revista Odontológica Mexicana 2012; 16(3):171-181.

9. Muller M, Berytrand MF, Quatrehomme G, Bolla M and Rocca JP. Macroscopic and microscopic aspects of incinerated teeth. The Journal of forensic odonto-stomatology 1998; 16(1):1-7.
10. Rossouw RJ, Grobler SR and Phillips VM. The effects of extreme temperatures on composite, compomer and ionomer restorations. The Journal of forensic odontostomatology 1999; 17(1):1-4.

11. Patidar KA, Parwani R and Wanjari S. Effects of high temperature on different restorations in forensic identification: Dental samples and mandible. Journal of forensic dental sciences 2010; 2(1):37.

12. Bose RS, Mohan B and Laxminarayan L. Effects of elevated temperatures on various restorative materials: an in vitro study. Indian journal of dental research: official publication of Indian Society for Dental Research 2005; 16(2):56-60.

13. Prakash AP, Reddy SD, Rao MT and Ramanand OV. Scorching effects of heat on extracted teeth-A forensic view. Journal of forensic dental sciences 2014; 6(3):186-90.

14. Sandholzer MA, Walmsley AD, Lumley PJ and Landini G. Radiologic evaluation of heat- induced shrinkage and shape preservation of human teeth using micro-CT. Journal of Forensic Radiology and Imaging 2013; 1(3):107-111.

\section{Author's Contribution:}

SS- Concept and design, review of literature, manuscript preparation, data collection, statistical analysis, critical revisions.

Work attributed to: Department of Pathology, College of Medical Sciences, Bharatpur Chitwan Nepal.

Orcid ID:

Dr. Sandeep Sharma - (1) https://orcid.org/0000-0001-7797-0273

Source of Support: Nil, Conflict of Interest: None declared. 